\title{
Algunas reflexiones sobre la jurisdicción castrense peruana
}

\section{Some Reflections on the Peruvian Military Jurisdiction}

*Arturo Antonio Giles Ferrer ${ }^{\star}$ https://orcid.org/0000-0001-6436-5461

http://dx.doi.org/10.21503/lex.v18i25.2115

*Presidente de la Sala Suprema de Guerra del Fuero Militar Policial del Perú hasta el 31 de diciembre de 2019, ex Secretario Técnico del Foro Interamericano de Justicia Militar. Abogado por la Pontificia Universidad Católica del Perú. Magíster en Derecho con mención en Ciencias Penales y Doctor en Derecho y Ciencia Política, grados otorgados por la Universidad Nacional Mayor de San Marcos.

Máster Universitario en Derecho Constitucional por la Universidad de Castilla - La Mancha. Magíster en Política Jurisdiccional por la Pontificia Universidad Católica del Perú. Egresado con trabajo académico del XXXVII Curso Interdisciplinario en Derechos Humanos, impartido en la sede del Instituto Interamericano de Derechos Humanos, San José, Costa Rica. Egresado de la National Defense University William J. Perry Center for Hemispheric Defense Studies, Strategic Implications of Human Rights and Rule of Law. Posgrado en Argumentación Jurídica y Función Jurisdiccional así como capacitación en Derecho Internacional Humanitario, Fuerza Pública y Derechos Humanos, estos dos últimos otorgados por la Pontificia Universidad Católica del Perú. Profesor de la Universidad Alas Peruanas en la Facultad de Derecho y Ciencia Política. Perú.

Correo electrónico: arturgf@hotmail.com

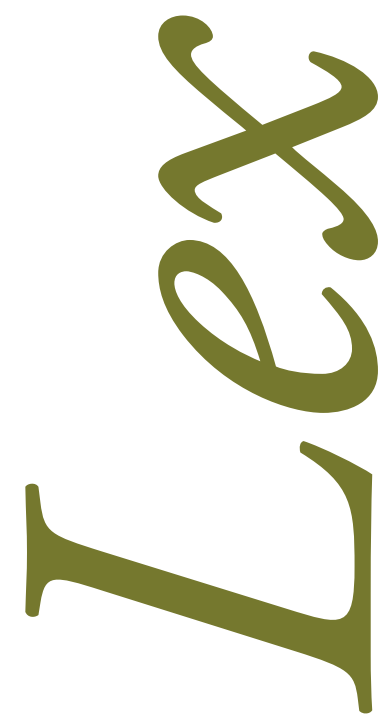






Ropavejero. Óleo sobre lienzo 46 × $35 \mathrm{~cm}$. Sonia Estrada Melgarejo (pintora peruana, Ancash) 


\section{RESUMEN}

Se plantea líneas de investigación de lo que se entiende debiera ser el trabajo intelectual, en justicia militar para los próximos ańos, en la inteligencia de consolidarla académicamente, en orden a construir una concepción peruana exportable de dicha jurisdicción especial, teniendo en cuenta además sus particularidades, que se originan en su ubicación entre los sistemas de justicia y defensa nacional así como en la Historia del Perú.

Palabras clave: justicia militar, modelo acusatorio, modelo inquisitivo, delito de función, Fuerza Armada, vía de evitamiento, justicia ejemplarizadora.

\section{ABSTRACT}

Research lines of what is understood should be intellectual work, in military justice for the next few years, in the intelligence of consolidating it academically, in order to build an exportable Peruvian conception of said special jurisdiction, also taking into account its peculiarities, which originate in its location between the justice and national defense systems as well as in the History of Peru.

Key words: military justice, accusatory model, inquisitive model, crime of function, Armad Force, avoidance route, exemplary justice. 


\section{INTRODUCCIÓN}

Las presentes reflexiones buscan actualizar y desarrollar las que escribí hace siete años ${ }^{1}$ en la publicación académica del Centro de Altos Estudios de Justicia Militar, con la distancia que da el tiempo y la indispensable objetividad a la que nos afiliamos.

En tal sentido, la justicia militar en nuestro medio y en general en varios estados del nuevo mundo, esa institución tan preciosa para asegurar la disciplina y moralidad en los Ejércitos, lamentablemente se sobreentiende, ello "autoriza" a los aficionados a pronunciarse, haciendo abstracción de sus peculiaridades, principalmente de su cercanía a la Fuerza Armada como el barro a las botas de los soldados, según conocida frase, sin tener en cuenta que la Fuerza Armada, "alma de la Nación", a decir de Hitler en "Mi lucha"2 está unida al país como la violencia lo es a la historia de la cual es su partera, a decir de Karl Marx.

Panorama desalentador, pues existen no pocos que la tratan por tener tribuna frente a ciudadanos desinformados y que obviamente no reparan en las imprecisiones incurridas, concretamente en ciertos medios de comunicación social, que muchas veces no son caja de resonancia de la opinión pública, sino que la forman. Es como si el micrófono o la pluma otorgaran una erudición que podríamos denominar adhesiva; resultando pues cuestionable tal proceder.

Pero eso no es sólo un problema peruano, ni siquiera de la época actual, siempre ha habido un marcado prejuicio respecto de la justicia castrense y las Fuerzas Armadas en general, como lo dijera el periodista, líder de la izquierda parlamentaria y Primer Ministro de la Tercera República francesa, Georges Clemenceau "la justicia militar es a la justicia lo que la música militar es a la música" y la escritora chilena, Isabel Allende de reconocimiento en su país y en el mundo dijo que: "la guerra es la obra de arte de los militares, la coronación de su formación, el broche dorado de su profesión. No han sido creados para brillar en la paz". Estas expresiones, aunque un tanto adornadas de poesía, como señala el Contralmirante chileno Cristian Araya ${ }^{3 “ . . . . c o n t i e n e n ~ u n a ~ v e r d a d e r a ~ d i a t r i b a ~ c o n t r a ~}$ los militares, porque ellas significan que los militares quieren la guerra y no la paz, que los militares

1. Arturo Antonio Giles Ferrer, "Apuntes para un estudio acerca de la justicia militar en el Perú”, en El Jurista del Fuero Militar Policial, número 2, noviembre (2013): 89-98.

2. Adolf Hitler, Mi Lucha, · Tomos I y II, (Alemania: Editorial Seckerand Warburg). La cita no impide mostrar nuestro desacuerdo con la pobre visión de la vida y del hombre que se describe en la mencionada obra.

3. Cristián Araya, "Bases jurídicas del nuevo código de justicia militar de Chile" en El Jurista del Fuero Militar Policial, publicación académica del Centro de Altos Estudios de Justicia Militar Año V, número 7/, Lima, julio (2016), 116. IMAGIDEAS.COM 
quieren la muerte y no la vida. Ello equivale a decir que el médico quiere y busca la enfermedad porque se ha preparado toda la vida para superarla, o que el abogado quiere y busca la injusticia porque se ha preparado toda la vida para luchar contra ella. Ello no es así: los militares nos preparamos para evitar la guerra y preservar la paz; para defender la vida y evitar la muerte, que no sea aquella propia, que estamos obligados a ofrecer en defensa de la Patria”.

En realidad, el asunto castrense resulta complejo, a decir de don José Ortega y Gasset ${ }^{4}$ en el libro "España invertebrada", "Medítese sobre la cantidad de fervores, de altísimas virtudes de genialidad, de vital energía que es preciso acumular para poner en pie un buen ejército. ¿Cómo negarse a ver en ello una de las creaciones más maravillosas de la espiritualidad humana? La fuerza de las armas no es fuerza bruta sino fuerza espiritual. Sólo quien tenga de la naturaleza humana una idea arbitraria tachará de paradoja la afirmación de que las legiones romanas y como ellas todo gran ejército, han impedido más batallas de las que han dado. El prestigio ganado en combate evita otros muchos, y no tanto por el miedo a la física opresión, como por el respeto a la superioridad vital del vencedor" y el ejército profesional, es un ejército disciplinado está seriamente comprometido con el respeto irrestricto a los Derechos Humanos y el Derecho Internacional Humanitario en clave de "República democrática, social, independiente y soberana”, como preceptúa el artículo $43^{\circ}$ constitucional que se aspira para el Perú, para que esa "continuación de las relaciones políticas.... gestión de las mismas por otros medios" a la que el alemán Karl Von Clausewitz llamaba Guerra y los especialistas, conflicto armado sea lo más humano posible y la disciplina sólo se consigue con una justicia militar sólida, independiente y autónoma y aquí conviene citar a un excelente militar y además el mejor cultor de las letras hispanas, me refiero a don Miguel de Cervantes Saavedra, el manco de Lepanto, quien siglos atrás dijera "las armas tienen por objeto y fin la paz, que es el mayor bien que los hombres pueden desear en esta vida". Nunca olvidemos que sin disciplina no hay orden, sin orden no hay seguridad, sin seguridad no hay crecimiento económico, sin crecimiento económico no hay desarrollo y precisamente para asegurar la disciplina está la justicia militar.

\section{ANÁLISIS DE LA JUSTICIA MILITAR EN EL PERÚ}

La legitimidad democrática de la justicia militar se deriva de la propia legitimación democrática de la Constitución, en la que ésta se entroniza. De ahí se desprende que la justicia castrense se fundamente en la estricta sujeción al programa penal de la Constitución, a los principios constitucionales del proceso y al Sistema de Defensa Nacional, atendida la circunstancia que la teleología que la anima es la protección de bienes jurídicos colectivos, militares, como la disciplina, sin la cual no puede hablarse con seriedad de Fuerza Armada, en un contexto de respeto irrestricto por los derechos humanos de sus integrantes y al cumplimiento de los roles constitucionales de las Fuerzas Armadas, los cuales apuntan a garantizar la independencia, soberanía e integridad territorial de la República, en el contexto del Estado Constitucional de Derecho, que de acuerdo a lo expresado, se postula para el Perú.

Es del caso puntualizar la importancia del nexo entre el principio de separación de poderes y la justicia militar. Al primero se le reconoce en la actividad estatal ordinaria funciones de muy diferente naturaleza material que si bien en su formulación clásica eran reconducibles a tres: legislar-legislativa-, gobernar con arreglo a ley-ejecutiva- y resolver los conflictos que pudieran suscitarse en la aplicación e interpretación de las leyes -judicial-actualmente, la Teoría del Estado nos enseña que el Poder,

4. José Ortega y Gasset, España Invertebrada, S.L.U. (Barcelona: Espasa Libros), 176. 
elemento del Estado, está distribuido en órganos que son mucho más que tres, los cuales se controlan entre sí -control interórgano- y al interior de cada uno -control intraórgano-, de acuerdo con la conocida tesis de Karl Loewenstein en su "Teoría de la Constitución" . Para el caso peruano, el Estado Constitucional, tiene base en la Constitución Política del Perú de 1993, concretamente en el artículo 43 del Título II: "Del Estado y la Nación", donde se preceptúa que el gobierno se organiza según el principio de la separación de poderes ${ }^{6}$.

De otro lado, la potestad de administrar justicia que a decir, del primer párrafo del Art. $138^{0^{7}}$ del código político peruano emana del pueblo y podemos afirmar sin temor a equivocarnos que ese baño de legitimidad, indispensable en democracia, se aplica también a la justicia militar, debe entenderse como aquel fin primario del Estado consistente en dirimir los conflictos. Ante la superación de la barbarie, propia de los estados fallidos, que significa hacer justicia por mano propia -salvo en los casos de legítima defensa, estado de necesidad o de derecho de retención-, corresponde al Estado en "El Contrato Social" de Juan Jacobo Rousseau ${ }^{8}$, resolver las controversias que surgen entre los ciudadanos. En dicho contexto, el justiciable tiene la posibilidad de recurrir ante el órgano jurisdiccional del Estado -que debe ser siempre autónomo-, para que se le haga justicia. De ahí se colige con claridad meridiana, que los caracteres indispensables para el ejercicio de la función jurisdiccional son exclusividad, independencia, responsabilidad, unidad, observancia del debido proceso, publicidad y cuanto enumera el Artículo $139^{\circ}$ de nuestra Carta" .

No obstante las similitudes relativas a la protección a los derechos humanos de quienes están sometidos a proceso, lo que se expresa en el cambio del modelo inquisitivo al acusatorio contradictorio ${ }^{10}$ en ciertos países de la Región y que no pocos estudiosos denominan más bien, adversarial y para otros es simplemente acusatorio, pero más allá de las etiquetas, hay significativas diferencias con la justicia ordinaria, toda vez que ésta prioriza cuando menos formalmente al reo, a quien debe reeducar, rehabilitar y reincorporara la sociedad, como preceptúa el Inciso 22 del Artículo $139^{\circ}$ de la Constitución peruana ${ }^{11}$, en tanto que para la jurisdicción castrense el énfasis está en el poder militar

5. Karl Loewenstein, Teoría de la Constitución, (Barcelona: Ariel 1986), 628.

6. Expediente No 0023-2003-PI/TC. La doctrina de la separación de poderes, que fue esbozada por John Locke, expuesta por Carlos de Secondat Barón de Montesquieu en su importante obra El espiritu de las leyes y la Brede y complementada en el siglo XX por Karl Loewenstein en su Teoría de la Constitución, tiene por esencia evitar, entre otras cosas, que quien ejerza funciones administrativas o legislativas realice función jurisdiccional y con ello desconozca derechos y libertades fundamentales.

7. Art.138․- "Función jurisdiccional.-La potestad de administrar justicia emana del pueblo y se ejerce por el Poder Judicial a través de sus órganos jerárquicos con arreglo a la Constitución y a las leyes. ........"

8. Juan Jacobo Rousseau, El contrato social, (Lima: Mercurio S.A.), 148

9. Arturo Antonio Giles Ferrer, "Apuntes para un estudio acerca de la justicia militar en el Perú", en El Jurista, Op. cit, 90-9.

10. Aunque no todo el inquisitivo es negativo, pues como recuerda el profesor Carlos Ramos Núñez, éste aporta la instancia plural, como el acusatorio trae el principio de publicidad.

11. Priorización que en el fondo sólo es formal, pues las cárceles están superpobladas, los internos hacinados y se constituyen en escuelas de post grado de la delincuencia y no son responsabilidad del Poder Judicial como insinúa nuestra Constitución sino del Ejecutivo. 
del país, a asegurar a cualquier precio. Ello es importante a tener en cuenta para ensayar un análisis objetivo de la jurisdicción castrense en la Región Andina.

Asimismo, la opción de jurisdicción castrense que asume un país está en función de su tratamiento de la Fuerza Armada. Así, en la República democrática, hay dos formas de concebir al Ejército, administrativista e institucionalista. Es propio de la caracterización administrativista de las Fuerzas Armadas, situarlas en órganos ejecutivos del Gobierno en particular y del Ministerio de Defensa en concreto, sin autonomía. Es el caso de aquellos estados que perdieron guerras importantes piénsese en Alemania o Japón y en nuestro continente de Argentina así como de los países que sin haber perdido quedaron devastados, tal el caso francés, que la reducen significativamente cuando no ladesaparecen; lo que polariza con la caracterización institucionalista que tiene una lectura institucional de los ejércitos, que incluye una cierta autonomía normativa, que esa la que alude el Art. $168^{12}$ constitucional, lo que refuerza a la jurisdicción castrense. En nuestro país, tal concepción se confunde con la administrativista aludida en las diversas leyes que se han dado para el Ministerio de Defensa así como en la Ley de Organización y Funciones del Ministerio de Defensa, aprobada por el Decreto Legislativo No1134 de 09 de diciembre de 2012, que trata al Ejército, Marina de Guerra y Fuerza Aérea como órganos ejecutores del Ministerio de Defensa, que es un apéndice del Gobierno. Empero hay mención a éstas en el Art. $165^{\circ 13}$.- de la Constitución peruana, no así al Ministerio de Defensa.

De otro lado, el derecho militar y penal militar así como la jurisdicción privativa han sufrido en su aplicación, distintos y fluctuantes contextos históricos, jurídicos, políticos y sociales, que han determinado los diferentes roles de las Fuerzas Armadas, propios de países subdesarrollados. ${ }^{14}$

Ello encuentra justificación en las conflictivas y en algunos estados, irresueltas relaciones civiles castrenses que fueron una constante en la historia de nuestros países ${ }^{15}$ y en la pobre acogida que tiene en las universidades del país el tratamiento del derecho militar. Las publicaciones nacionales relativas a la jurisdicción castrense resultan insuficientes y tienen su origen en juristas de la Pontificia Universidad Católica del Perú, Universidad Nacional Mayor de San Marcos y Universidad Nacional de Trujillo, Defensoría del Pueblo, Instituto de Defensa Legal y el Consorcio Justicia Viva. Tales investigaciones apostaban por la desintegración de la jurisdicción privativa en tiempo de paz ${ }^{16}$.

12. Art.168.-"Organización y funciones de las Fuerzas Armadas y Policía Nacional..-Las leyes y los reglamentos respectivos determinan la organización, las funciones, las especialidades, la preparación y el empleo; y norman la disciplina de las Fuerzas Armadas y de la Policía Nacional.

Las Fuerzas Armadas organizan sus reservas y disponen de ellas según las necesidades de la Defensa Nacional, de acuerdo a ley".

13. Art.165‥ “...Las Fuerzas Armadas están constituidas por el Ejército, la Marina de Guerra y la Fuerza Aérea..."

14. Es útil mencionar, que en el Perú, el Dictamen No 08 de fecha 25 de septiembre de 2007, aprobado por unanimidad por la Comisión de Defensa Nacional, Orden Interno, Desarrollo Alternativo y Lucha contra las Drogas, cuya Presidenta era la Congresista Mercedes Cabanillas de la Alianza Popular Revolucionaria Americana (APRA), tomó en cuenta el aspecto de las coyunturas políticas, 3 .

15. Que tendrían que ser objeto de un análisis que por razones de contexto, no corresponde hacer ahora.

16. Los siguientes son, enunciativamente, los principales estudios e investigaciones en materia de jurisdicción militar: Samuel Abad Yupanqui, "Garantías Constitucionales: delimitando las fronteras de la justicia militar", en Debate Defensorial, revista de la Defensoría del Pueblo No 1, Lima: setiembre (1998). César Azabache, sobre "La pena de muerte en la Constitución 
Pero también los hay que apuntan a la permanencia de una institución que es incluso anterior a la República ${ }^{17}$, sustancialmente a cargo del ex Consejo Supremo de Justicia Militar (CSJM), el actual Centro de Altos Estudios de Justicia Militar y algunos pocos juristas nacionales.

de 1993. Análisis y Comentarios”, Serie: Lecturas sobre Temas Constitucionales 10, (Lima: Comisión Andina de Juristas, 1994). De nuevo "La justicia militar. En: La Constitución de 1993", Análisis y Comentarios, Serie: Lecturas sobre Temas Constitucionales 10, (Lima: Comisión Andina de juristas, 1995). Enrique Bernales Ballesteros, Comentarios a la Constitución Política del Perú, RAO, Lima, 1999. Emilia Bustamante Oyague, "El Juzgamiento de civiles por los tribunales militares: Transgresión del derecho a ser juzgado por un Tribunal competente, independiente e imparcial. El Caso Cantoral Benavides", en Revista Peruana de Jurisprudencia. Año 4, Número 15, mayo (2002). Edgar Carpio Marcos, "La cláusula de la pena de muerte en una Opinión Consultiva de la Corte Interamericana de Derechos Humanos -Violación de la Convención y responsabilidad Internacional-“, en, Apuntes de Derecho, Año I, No 1. (Lima: Editorial San Marcos, octubre 1996). Francisco Rogger Carruitero Lecca, La Jurisdicción Militar en el Perú: Desarrollo histórico y problemática actual, (Espańa, Toledo: 2010), 213. Javier De Belaunde, "Lineamientos para la reforma de la justicia militar en el Perú", en: Meta política. Volumen 2, Número 7, México, julio - setiembre de (1998). Defensoría del Pueblo, "Lineamientos para la reforma de la justicia militar en el Perú", Serie Informes Defensoriales, Informe No 6, 57. 64, 66, 104. Christian Donayre Montesinos, "Una propuesta frente a la crisis histórica del ejercicio de la jurisdicción militar en nuestro país y la necesidad de la adecuación de sus lineamientos a los parámetros de un Estado de Derecho", en Revista Derecho \& Sociedad, editada por estudiantes de la Facultad de Derecho de la Pontificia Universidad Católica del Perú, Año XII, No 17, Lima, diciembre (2001). Y otros estudios, Gerardo Eto Cruz, "El Régimen Constitucional de la Justicia Militar en el Perú", en Dereito, revista Xurídica da Universidad de Santiago de Compostela. Vol. 5, No 2, (Santiago de Compostela: Servicio de Publicaciones de la Universidad de Santiago de Compostela, 1996), La Justicia militar en el Perú, (Perú, Trujillo: Empresa editora Nuevo Norte S.A enero 2000). Gerardo Eto Landa; César Landa Arroyo y José F. Palomino Manchego, "La Jurisdicción Militar en el Perú", en Bidart Campos y José Palomino Manchego (coordinadores). Jurisdicción Militar y Constitución en Iberoamérica. Libro Homenaje a Domingo García Belaunde, (Lima: Grijley, 1997). José Francisco Gálvez Montero, "La Reforma de la Justicia Militar al compás de la Constitución”, en La Justicia Militar en el Derecho Comparado y en la Jurisprudencia Constitucional, (Lima: Palestra, 2009). Domingo García Belaunde, "La Jurisdicción Militar en América Latina -la unidad de jurisdicción en algunos países del área”, en Revista Jurídica del Perú, Año XLVII, No 13, Trujillo: Editorial Normas Legales, Octubre Diciembre (1997). José Hurtado Pozo, -Director- y Yolanda Doig Díaz, -coordinadora-, "La Reforma del Derecho Penal Militar”, Anuario de Derecho Penal (2001 - 2002), Lima: Fondo Editorial de la Pontificia Universidad Católica del Perú y Universidad de Friburgo, (2002), en este Anuario se publicaron los siguientes estudios: José María Asencio Mellado, "Reflexiones en torno al proceso penal militar peruano. Un proceso inquisitivo"; Yolanda Doig Díaz, "La justicia militar a la luz de las garantías de la jurisdicción, en: La reforma del derecho penal militar"; Iván Meini, "Observaciones en torno a la Parte General del Código de Justicia Militar". Roberto Carlos Pereira Chumbe, "Evolución legislativa de la justicia militar en el Perú, la reforma del Derecho Penal Militar"; Pablo Sánchez Velarde, "El Ministerio Público en la Justicia Militar"; Juan Carlos Sandoval, "Legislación de emergencia y especialidad del delito militar"; César San Martín Castro, "Algunos aspectos de la justicia militar -a propósito del caso peruano-”. David Lovatón, Jurisdicción Militar: Una cuestión de principios, (Lima: Instituto de Defensa Legal, 1998). Iván Meini, “Objeciones al Proyecto de Código de Justicia Militar”, en: Legal Express, Año 3, No 36. Lima: Gaceta Jurídica, diciembre (2003). Francisco Saravia Morales, "Comentarios sobre la sentencia de Hábeas Corpus a favor de Gustavo Adolfo Cesti Hurtado y las consecuencias de su tardío cumplimiento por el Consejo Supremo de Justicia Militar”, en Diálogo con la Jurisprudencia Número 14. Lima: Gaceta Jurídica, noviembre (1999). Carlos Rivera Paz, Justicia Militar y Derechos Humanos, (Lima, junio 2001-separata-). Luis Sáenz Dávalos, "Jurisdicción común vs. Jurisdicción militar -Reflexiones sobre la controversia funcional”, en Lecturas sobre Temas Constitucionales 15. Lima: Comisión Andina de Juristas, (1990). César San Martín Castro, "Apuntes en torno a la jurisdicción castrense”, en Revista Jurídica del Perú, Año LII, No 37, agosto (2002). Teresa de Jesús Seijas Rengifo, "Hacia una reforma de la Administración de justicia en el fuero privativo militar”, En Revista del Foro, No 2, Lima: Dirección de Comunicaciones en Informática Jurídica, (2001).

17. Cfr. Francisco Carruitero Lecca, "La reforma de la justicia penal militar en el Perú: una mirada a los límites a la libertad de configuración penal del legislador y los recientes cuestionamientos al fuero militar", en Jus Constitucional No 4 (Lima, Grijley, 2008). Gustavo Gutierrez, "Justicia Militar: una posición en defensa de las competencias del Congreso de la República”, en Jus Constitucional No 4., (Lima, Grijley 2008). Juan Pablo Ramos Espinoza, Derecho Penal y Procesal Militar, Ediciones Jurídicas, Lima, 2005. 
En el Perú, debe tenerse en cuenta asimismo, las sentencias del Órgano de control de la Constitución que ha dictado diez resoluciones ergaomnes, las ocho primeras contrarias a la jurisdicción castrense. Recién con la novena del 22 de diciembre de 2009, el Tribunal Constitucional mudó su tendencia. La décima sentencia es la No022-2011-PI/TC de 08 de julio de 2015, en la que se le quita a la justicia militar el conocimiento de los delitos contra el Derecho Internacional Humanitario, delitos, y eso es lo grave del tema, que tampoco están tipificados en el fuero común. En consecuencia, nuestra justicia militar, queda básicamente diseñada para el tiempo de paz. Ello sugiere ejercer nuestro derecho de formular análisis y críticas de las sentencias a que se contrae el Inciso 20 del Artículo $139^{\circ}$ de la Constitución, a fin de la conveniencia de mantener este modelo que resulta concorde al principio de Supremacía constitucional y a la autonomía de tipificación del Congreso, teniendo en cuenta las particularidades de esta jurisdicción especializada, conceptualizan dolos interés es jurídicamente relevantes a proteger en sede penal militar, que son sustancialmente colectivos y tienen que ver directamente con los roles constitucionales de la Fuerza, lo que a su vez hará posible diferenciar el injusto militar según los diferentes ordenamientos ${ }^{18}$, de la falta disciplinaria.

Menos aun la historia puede dejarse de lado, pues en ella las instituciones actúan en circunstancias muy concretas, que son resultado de circunstancias anteriores y que producirán a su vez circunstancias futuras.

Desde esa perspectiva, los sucesos históricos son relevantes a fin de tener una correcta inteligencia, de esta jurisdicción especial. Desde esta perspectiva, el Centro de Altos Estudios de Justicia Militar ha avanzado bastante, pues ha producido tres tomos de "La Justicia Militar en la Historia del Perú"19 que van desde antes de Roma hasta el Código de justicia militar de 1950, pero queda pendiente tal vez la etapa más importante, la de su uso por el Poder Político como vía de evitamiento, que es precisamente la que determina porqué la justicia militar "es como es y hacia dónde va, pues la historia, maestra de la vida como diría Cicerón, obliga a reconstruir momentos de la justicia militar no conocidos, con el propósito de mejor comprender la realidad militar actual y la ubicación en la organización de nuestros estados, de una institución que ha pervivido a lo largo de la República, desde que la autoridad, al colocar las bases de la teoría clásica de la separación de poderes, reconoció la existencia de los fueros ordinario, militar, universitario, de indios y eclesiástico distinción que fue ratificada en constituciones peruanas posteriores, fueros que hoy se baten en retirada pues al ser personales, colisionan con el principio de igualdad ante la ley.

Los fueros corresponden a una forma de organización del poder que es previa al estado moderno, anterior al constitucionalismo, se sustentan en la organización estamental de la sociedad, donde los derechos y obligaciones de las personas se definían en función de su pertenencia a determinada corporación o estamento y no a su condición de sujetos libres e iguales. El único fuero que ha sobrevivido es el parlamentario y no en todos los países. En Colombia por ejemplo, no existe la

18. Lo expresado en este párrafo puede resultar de aplicación también para los sistemas de justicia militar de los países de América.

19. El tomo I publicado en el 2017 bajo la autoría del profesor José Francisco Gálvez Montero, que va hasta el Consejo Supremo de Guerra y Marina en 1899, 268 páginas, los tomos II y III a cargo del Teniente Coronel EP ${ }^{\circledast}$ Alejandro Roosevelt Bravo Maxdeo 428-465. 
inmunidad parlamentaria. ${ }^{20}$ Por ello, hoy resulta discutible hablar con propiedad de un fuero militar porque es un concepto medieval, anticuado y poco feliz pese a que literalmente la Constitución peruana se refiere a él en el artículo $173^{\circ}{ }^{\prime 21}$.

En realidad es sólo un problema semántico, desde que la competencia de la justicia militar peruana está directamente vinculada al delito de función de acuerdo con el Art.173 ${ }^{22}$ de la Constitución peruana. Por ello más técnico resulta aludir a la expresión jurisdicción militar que es una jurisdicción especial.

Como se indica en la página 9 del Informe Defensorial $\mathrm{No}^{23}$, "la existencia de un ordenamiento jurídico militar autónomo..." y diferente pero siempre subordinado al ordenamiento jurídico nacional es y ha sido la constante en las "sociedades a lo largo de la historia". Por ello, los antecedentes históricos constituyen un inteligente punto de partida y pretenden ofrecer una visión global de la justicia castrense particularmente en lo relativo a la competencia y composición orgánica de sus tribunales.

Históricamente y para hacer breve el asunto, la justicia militar peruana, como la de otros estados del continente americano, es una herencia de la justicia militar española del siglo XIX, que era una justicia castrense inquisitiva, poco profesional, administrada por oficiales de armas, basada en el in dubio pro disciplina, irrespetuosa del principio de legalidad, utilizada muchas veces por la parte política como vía de evitamiento para hacer control social, desprestigiada, tratada por los Institutos Armados como patio trasero, donde se enviaba a los oficiales de armas menos caracterizados, como un caramelo a quienes estaban próximos a pasar a la situación militar de retiro. Esto es a la evidencia, penosamente cierto.

Y esto llegó a su punto más álgido durante el Gobierno del Presidente Fujimori, en que incluso se le encargó la investigación y juzgamiento de civiles que cometían el denominado delito de terrorismo agravado y robos en banda. Cuando aparecieron los llamados "vladivideos", el régimen fujimorista se desmoronó y se alzaron voces contra las Instituciones instaladas en la Constitución peruana de 1993 y contra la propia Constitución. Obviamente, la justicia militar no era una excepción, llegando a cuestionar hasta su propia existencia. Se declaró la inconstitucionalidad de las leyes que otorgaban a la jurisdicción castrense competencia para juzgar civiles y por hechos punibles diferentes al delito de función y por ende nulos dichos procesos, sin embargo, dato curioso, ningún condenado salió en libertad.

Así las cosas, o la justicia militar cambiaba o desaparecía y decidió cambiar. Hoy se cuenta con una justicia militar policial profesional, administrada por abogados con grado militar o policial, integrantes del cuerpo jurídico militar, en el marco de un proceso acusatorio, respetuoso del debido proceso

20. Y en el Perú la inmunidad parlamentaria extendida indebidamente a los magistrados del Tribunal Constitucional, se bate en retirada.

21. Arturo Giles: “Apuntes para un estudio acerca de la justicia militar en el Perú”, en El Jurista Op. cit., 94.

22. Art.173‥ “...En caso de delito de función los miembros de las Fuerzas Armadas y de la Policía Nacional están sometidos al fuero respectivo y al Código de Justicia Militar...."

23. Defensoría del Pueblo, Informe Defensorial No.6. Lineamientos para la reforma de la justicia militar en el Perú, (Lima: Editorial Trama Azul Editores, 1998). 
legal, teniendo en el vértice superior a la Sala Revisora ${ }^{24}$ integrada exclusivamente por Generales y Almirantes en retiro ${ }^{25}$, sin relación de subordinación alguna con las Fuerzas Armadas y Policía Nacional y constreñida exclusivamente a delitos de función imputados al personal militar o policial en situación de actividad.

Cierto es que el cambio de las leyes no importa necesariamente cambio en el esquema mental de los operadores jurisdiccionales y fiscales. Concretamente, en el trabajo de no pocos se advierte rezagos del viejo sistema inquisitivo.

Urgen pues aproximaciones profesionales sobre la jurisdicción castrense peruana en especial y andina en general, en estricta sujeción a los derechos humanos en clave democrática, en función de su devenir histórico pero con una lectura actual, para nuestros países. Hay ciertos trabajos sobre la jurisdicción castrense, empero carecemos de una caracterización peruana y continental ${ }^{26}$ y hoy es urgente asignar contenidos a nuestros códigos castrenses, trabajar sobre sus problemas de aplicación, concretamente en lo relativo al proceso acusatorio, ordenar el trabajo de los colegiados castrenses y la doctrina jurisdiccional en materia penal militar, que oriente la actuación de los operadores jurisdiccionales y jurisdiccionales requirentes de la justicia castrense, cuya aprobación para el caso peruano, corresponde al Consejo Ejecutivo del Fuero Militar Policial con arreglo a lo preceptuado por el Inc. 6 del Art. $5^{027}$ de la Ley de Organización y Funciones del Fuero Militar Policial, modificada por la Ley 29955 de 06 de diciembre de 2012 y del Pleno del Tribunal Supremo Militar Policial, para los acuerdos de doctrina jurisprudencial, a que alude el Art. $8^{\mathrm{o} 28}$ de la citada Ley de Organización, aun cuando esto último debería ameritar estudios más profundos para determinar los límites de la doctrina y el órgano competente para producirla.

Asimismo, es indispensable el tratamiento de la jurisdicción castrense en los distintos sistemas que ofrece el Derecho extranjero. En efecto, parafraseando a Fernández Segado ${ }^{29}$, el estudio extranjero

24. El Poder Judicial, a través de la Corte Suprema conoce exclusivamente de contiendas de competencia entre el Fuero Común y el Militar y cuando se aplica la pena de muerte por traición a la patria, supuesto este último inviable constitucionalmente, de acuerdo a los artículos $141^{\circ}$ y $173^{\circ}$ de la Constitución, artículos $3^{\circ}$ y $4^{\circ}$ de la Ley.

25. Ley de Organización y Funciones del Fuero Militar Policial, aprobada por Ley 29182, modificada parcialmente por la Ley 29955.

26. Al respecto, es útil y justo mencionar que en el Perú se hacen importantes esfuerzos en este sentido, precisamente a cargo del Centro de Altos Estudios de Justicia Militar que ha venido realizando eventos nacionales e internacionales, cursos de capacitación, hasta tres publicaciones que contienen interesantes estudios al respecto, empero todavía éstos resultan insuficientes y el mismo panorama se puede apreciar en los países del continente.


jurisdiccionales y fiscales del Fuero Militar Policial”.

28. Art.8º- "Naturaleza y sede.- El Tribunal Supremo Militar Policial es el máximo órgano jurisdiccional del Fuero Militar Policial. Su sede es la ciudad de Lima. Para el ejercicio de sus funciones jurisdiccionales, el Tribunal Supremo Militar Policial se organiza en una Sala Suprema Revisora, una Sala Suprema de Guerra y una Vocalía Suprema. Actúa como Pleno para los acuerdos de doctrina jurisprudencial. Por acuerdo de Sala Plena, a propuesta de su Presidente, se podrán constituir otras Salas en función de los asuntos que le sean sometidos a su consideración".

29. Francisco Fernández Segado, "La Jurisdicción Militar en la Constitución española 1978. Su organización y ámbito competencial”. En Jurisdicción Militar y Constitución Iberoamericana, (Lima: Grijley,1997): 131-232. 
de las instituciones jurídicas resulta de la mayor importancia como lo sostienen Biscaretti ${ }^{30}$ y Sánchez Agesta $^{31}$ entre otros autores, atendida la circunstancia que conjuntamente con este rol formativo, la comparación cumple otras finalidades que van desde la elaboración de un concepto tipo o de un modelo -no olvidemos que ya el estagirita estudió los textos constitucionales de la antigüedad, comparándolos para inferir de sus tópicos una caracterización axiológica que posibilitara la construcción de un modelo de constitución perfecta- hasta obtener lo que se suele llamar un contraste de particularidades -el autor de "El espíritu de las leyes", comparaba para una mejor comprensión de las particularidades de las instituciones de diferentes estados-, teniendo en cuenta que el estudio comparado es particularmente valioso de cara a repensar creativamente las instituciones, según la fuente de Pablo Lucas Verdú ${ }^{32}$. El aporte del Derecho Comparado enclave de política legislativa o sea, de la nomotética, es importante, atendida la circunstancia que, el conocimiento de la legislación e institutos de países con modelos análogos resulta indispensable en orden a hacer frente a los retos que se expresen en nuestros sistemas jurídicos y particularmente en lo relativo a la jurisdicción privativa.

Tal estudio, tiene que llevarse acabo de cara a la jurisdicción castrense hispana, sin copiarla. No caigamos en lo que el profesor José Hurtado Pozo criticaba en su libro "La Ley importada" Nuestro país, como se expresó, adoptó el sistema gaditano, tanes así que la abrogada Ley No 28665 de Organización y Funciones de la Jurisdicción Especializada en lo Militar Policial, del año 2005, bebió de la justicia castrense de la madre patria, creando una Sala Suprema Militar al estilo de la Sala Quinta del Tribunal Supremo de España, influenciado a su vez por el sistema italiano, según la fuente de Rodríguez Villasante ${ }^{33}$. No obstante lo cual, tal ley fue expulsada del ordenamiento jurídico por el Guardián de la Constitución.

Empero, constitucionalmente, las diferencias son sustanciales y saltan a la vista, pues el principio de unidad tanto en Espańa cuanto en nuestro país, está contenido en las dos normas fundamentales, pero con teleologías diferentes. Con relación a la función judicial, en estrictez jurídica, tal mandato de optimización en términos de Manuel Atienza, constituye el cimiento de la organización y funcionamiento de los colegiados. Con relación a los operadores de dicha jurisdicción, constituyen un cuerpo único y los uniformados su estatuto jurídico particular, pero conectado en el vértice superior al Poder Judicial mediante el recurso de casación como lo proclama el citado Art. $141^{\text {o } 34}$ concorde con el Art. $173^{\mathrm{o}^{35}}$ de la Constitución Peruana y que como se sabe, no es otra cosa que un rezago del llamado Estado de Derecho francés.

30. Paolo Biscaretti di Ruffia, Introducción al Derecho Constitucional Comparado, (Las formas de Estado y las formas de gobierno. Las Constituciones modernas), (México: Fondo de Cultura Económica, 1975), 14.

31. Luis Sánchez Agesta, Curso de Derecho Constitucional comparado, Facultad de Derecho, Universidad Complutense, (Madrid: 5a ed., 1973), 21.

32. Pablo Lucas Verdú, Curso de Derecho Político, Vol. I, (Madrid: Editorial Tecnos, 1972), 415.

33. José Luis Rodríguez-Villasante y Prieto, "Estudio de Derecho comparado sobre la organización de la jurisdicción militar en diversos países", en Revista Española de Derecho Militar (en adelante REDEM), №53, Tomo I, enero-junio (1989): 57 63.

34. Art.141.-“Casación.-Corresponde a la Corte Suprema fallar en casación, o en última instancia, cuando la acción se inicia en una Corte Superior o ante la propia Corte Suprema conforme a ley. Asimismo, conoce en casación las resoluciones del Fuero Militar, con las limitaciones que establece el artículo $173^{\circ}$."

35. Art.173․-"Delitos de función.- En caso de delito de función, los miembros de las Fuerzas Armadas y de la Policía Nacional están sometidos al fuero respectivo y al Código de Justicia Militar. Las disposiciones de éste no son aplicables a los civiles, salvo en el caso de los delitos de traición a la patria y de terrorismo que la ley determina. La casación a que se refiere el artículo 141 sólo es aplicable cuando se imponga la pena de muerte. Quienes infringen las normas del Servicio Militar Obligatorio están asimismo sometidos al Código de Justicia Militar”. 
No escapará a la comprensión del lector atender, que tanto nuestro país cuanto los de la región andina se ubican en el sistema eurocontinental al igual que Italia y España, que posibilita la presencia de colegiados castrenses permanentes. Aquí se justifica por el particular con texto sociopolítico con elementos subversivos de Sendero Luminoso, en el Valle de los Ríos Apurímac, Ene y Mantaro. En el país del norte, la existencia de las Fuerzas Armadas Revolucionarias de Colombia, aún con la llamada "justicia transicional", le ha permitido desarrollar su derecho operacional. Asimismo, resulta indispensable reflexionar acerca de los sistemas de jurisdicción castrense más importantes, entendiendo en algunos casos los motivos de su desaparición. Los dedos de las manos sobran para contar a los países que teniendo Fuerzas Armadas, carecen de algún sistema de investigación y eventual sanción penal de los uniformados.

Asimismo, debe entronizarse a nuestras justicias militares en el Sistema de Defensa Nacional de nuestros países y tener en cuenta la autonomía de que gozan los congresistas para, en el marco de la Constitución, legislar en materia penal y vincular los injustos militares con el Sistema de Defensa Nacional en clave de las funciones constitucionales de las Fuerzas Armadas. Asimismo, debe desarrollarse conceptualmente el bien jurídico "potencial bélico de la nación” y el tratamiento que los tribunales constitucionales u órganos equivalentes en los diferentes países del continente han dado a los delitos de función o militares. En el Perú por ejemplo, la justicia militar no depende ni del Poder Ejecutivo ni del Judicial, sino que forma parte integrante tanto del Sistema de Defensa como del de Justicia, de ahí sus particularidades. Como se expresó, el desarrollo necesita del crecimiento económico y este último sólo se da en un ambiente de seguridad y orden, para lo cual se necesitan Fuerzas Armadas y Policiales disciplinadas y es ahí donde interviene la justicia militar, para prevenir y asegurar esa disciplina así como sancionar su quebrantamiento.

En nuestro país, tratamiento adicional amerita la Ley 29955 de 06 de diciembre de 2012, modificatoria parcialmente de la Ley 29182 Ley de Organización y Funciones del Fuero Militar Policial con objetividad y lejos de las pasiones del ahora actual.

Viene quedando meridianamente claro que nuestras justicias militares no son un invento moderno, tampoco son la creación de genio alguno, no son minerva armada del cráneo de Júpiter, lo nuestro es el resultado de un largo y lento proceso de evolución, no es expresión de arbitrariedad ni de exceso. La jurisdicción castrense es una vetusta institución que ha sobrevivido a los cambios imperantes en el país y si en algunos países y en ciertas ocasiones, la parte política hipertrofió sus competencias, ello no fue su responsabilidad. Siempre pretendió la preservación del orden, disciplina y moralidad en los cuarteles.

"Su naturaleza jurídica es esencialmente ejemplarizadora y sus principios rectores son generalmente uniformes en los países que tienen fuerzas armadas y policía militarizada" 36 . Hay estados que al no tener Fuerza Armada, tampoco tienen justicia militar, tales los casos de Costa Rica, Panamá, Haití entre otros.

De otro lado, dentro del noble menester de administrar justicia están los operadores de la justicia militar en su misión excepcional y constitucional de aplicar los códigos a los castrenses y eventualmente policías que cometen delito de función o delito militar según los ordenamientos. Dada la trascendencia

36. Arturo Giles, Op. cit., 97. 
de la finalidad primordial de las fuerzas armadas y el fin fundamental de las policías nacionales, esta jurisdicción tiene un buen nivel que no debe perder, toda vez que los que están a cargo, poseen la certeza de servir al país al que en última instancia se deben, en función de una delegación dada por la sociedad y como garantía de acierto y justicia así, esta jurisdicción preserva la disciplina, la moralidad y el orden en las fuerzas armadas y en la policía nacional y ante la sociedad es garantía plena de tal cometido, actuando con criterio de hoy y no de ayer.

El magistrado militar pues, ejerce una de las más nobles profesiones. Es en realidad el guardián de la disciplina y moralidad en las FFAA, pues no puede haber fuerza armada sin justicia militar ergo: ni una, ni otra sin el concurso de los magistrados militares, binomio históricamente inseparable, por lo tanto, la función del magistrado militar no necesita ser demostrada, es evidente por sí misma.

"De otro lado, la independencia de los magistrados civiles o militares que están en la situación militar o policial de actividad, como la de cualquier magistrado del fuero común, debe encontrarse en última instancia, es decir, antes que en las leyes o en las Instituciones que por ser hechuras humanas resultan imperfectas, en su propia conciencia y en la rectitud de ánimo de las fuerzas políticas que deben ver en el juez, el último bastión en la preservación del estado de derecho constitucional". ${ }^{37}$

Bienaventurados quienes tienen hambre y sed de justicia dice el Galileo en el Sermón de la Montaña y para saciarlos el magistrado militar policial, impregnado por la geometría moral de las líneas verticales, con el coraje de la verdad como diría el viejo Hegel, está llamado a ser un sacerdote de la justicia a través de los evangelios de la ley, ya que su responsabilidad es terrible, habida cuenta de la variedad de casos y situaciones que se presentan y porque además sienta jurisprudencia y en el Perú el Tribunal Supremo Militar Policial, cuya sobria y monumental arquitectura es un homenaje a la norma jurídica hecha ley y aplicada justicieramente, es la sede en la que se administra esta justicia militar policial al más alto nivel.

"Una correcta inteligencia de la necesidad de la Justicia Militar en el mundo, pasa por entender que existen fusionadas dos sociedades diferentes pero complementarias, la sociedad de la igualdad y la libertad en la que actúa el Juez Civil y la sociedad de la obediencia en la que opera el Juez Militar preservando la jerarquía, la disciplina, la eficacia operativa, la integridad institucional, los deberes militares y policiales, el potencial bélico de la nación y la fidelidad a la función militar policial"38, por ello la concebimos como "Justicia que forja disciplina", aun cuando hay quienes cuestionan esta expresión, por cuanto la disciplina no es lo único que se preserva en la jurisdicción castrense.

La justicia militar de los estados de la Región Andina, por encima de las diferencias de todo tipo, culturales, jurídicas, sociales, institucionales, etc., enfrentan problemas y rechazos similares, provenientes de quienes pretenden su desaparición o reducción, pero también existen objetivos comunes como su razón de ser, ya que en casi todos los estados del mundo ellas mantienen el potencial bélico de la nación, entendido en el más amplio sentido de la palabra y en relación con el cumplimiento de las misiones que las constituciones políticas de los estados asignan a sus fuerzas armadas y policías nacionales.

37. Ibídem.

38. Arturo Giles, Op. cit., 97. 
Como se aprecia pues, se ha avanzado bastante, nuestra justicias militar se está asentando en los entornos nacionales y es reconocida por el Sistema Interamericano de Derechos Humanos; además, suma a su antigüedad, no solamente la adquisición de conocimientos lógica consecuencia del transcurso tiempo transcurrido, más importante aún, su adaptación a las nuevas misiones de los Ejércitos con liderazgo en la Región Andina, no obstante lo cual, los tiempos por venir exigen todavía más cambios estructurales si se quiere entrar en la galería mística del recuerdo y la gratitud de las generaciones postreras, la responsabilidad es pues terrible, pues lo contrario puede significar pasar a la historia como víboras cuya historia no recuerda y merecen su desprecio y olvido y ser como diría Juan Vicente Ugarte del Pino en la introducción a su importante obra Historia de las Constituciones del Perú 39 , "Capitanes que, en el naufragio ante la mirada consternada de los demás, se alejaban de la nave que se hundía irremediablemente".

En ese orden de ideas, nuestras justicias militares vienen experimentando una importante transformación y un imperativo categórico kantiano las obliga a cambiar a la par de la evolución social, pues de lo contrario van a desaparecer y en la responsabilidad de sus operadores está garantizar a nuestros estados, justicias militares, independientes, autónomas, para asegurar los fines de honda raigambre histórica que fundamentan la existencia de las Fuerzas Armadas, en nuestras constituciones, consolidando de ese modo, reales Estados de Derecho Constitucional para los países del continente.

Y esto es así, porque "las instituciones a diferencia de los satélites, rara vez se quedan en el lugar en el que los diseñó su creador y nuestras justicias militares son un buen ejemplo de esa dinamicidad que nos muestran las instituciones del derecho público en su afán por adecuarse a los nuevos vientos" 40 , coadyuvando con ello al crecimiento de justicias militares modernas y estratégicas para nuestros estados y las sociedades en general.

"Finalmente, siendo como es, el mandato a término, así como la efectiva responsabilidad de quienes vestimos uniforme, no sólo uno de los fundamentos básicos del sistema democrático, sino también aspiración proclamada en nuestras constituciones, resulta en consecuencia indispensable que todos, autoridades, funcionarios, profesionales, civiles y militares, policías, estudiosos, estudiantes, políticos etcétera, nos preocupemos en asegurarle a nuestro país y a nuestro estado, una justicia militar sólida, independiente, autónoma, absolutamente respetuosa de los derechos fundamentales y notas características del debido proceso legal de militares y policías sin el cual nunca puede hacerse realmente justicia, pero severa frente a aquellos malos militares y policías, que felizmente son los menos, quienes animados por propósitos subalternos, ajenos a la moralidad o a la defensa de la legalidad, usan o pretenden usar los honores, grados, cargos, uniformes y armas que nos otorgan nuestra nación, para abusar o enriquecerse al calor de enardecidas pasiones, desvirtuando con ello, los fines de honda raigambre jurídica e histórica que fundamentan la existencia misma de las fuerzas armadas y policiales y nuestra justicia militar que no se entiende sin aquellas, pero cuya imagen jamás podrán ser dañadas por esos oscuros personajes, cuyos nombres la historia de nuestro pueblo no recuerda y que merecen su desprecio y olvido" 41 , que transitan como víboras por la puerta falsa de la historia de nuestra nación,

39. Juan Vicente Ugarte del Pino, Historia de las Constituciones del Perú, (Lima: Andina S.A., 1978).

40. Arturo Antonio Giles Ferrer: "Epílogo Oteando el futuro de la justicia militar en América”, II Foro Interamericano sobre justicia militar y derecho operacional, (2014): 122. Lima: Centro de Altos Estudio de Justicia Militar.

41. Arturo Giles, "Apuntes para un estudio acerca de la justicia militar en el Perú”, Op. cit., 96. 
debiendo ser condenados a la estigmatización permanente, sin los honores y pensiones que el estado les asigne y quedar sujetos al proceso y eventual sanción penal que les corresponda según las leyes respectivas, parafraseando a Hamilton, Madison y Jay, en su famosa obra intitulada, "El Federalista".

Cada perspectiva y análisis resulta de gran ayuda para reforzar y mejorar nuestra justicia militar; asimismo, invita a conocer nuevos enfoques sobre los criterios jurídicos del derecho operacional que encuentran complementariedad a la hora de fijar el marco legal de las operaciones militares y policiales, que tienen como fin garantizar la paz y la seguridad, ya que en un ámbito pluralista se pueden discutir finamente los planteamientos y arribar a las mejores tesis para nuestro querido país. Debemos construir un "Derecho para la Paz" y en ese orden de ideas, resulta indispensable un ejercicio de reflexión colectiva con relación al tratamiento de la jurisdicción castrense en nuestro continente, que no obstante su antigüedad de más de quinientos ańos, genera siempre debate.

En el Capítulo 3 del Libro del Eclesiastés se dice y cito textualmente: "hay bajo el sol un momento para todo, y un tiempo para hacer cada cosa; tiempo para nacer y tiempo para morir, tiempo para plantar y tiempo para arrancar lo plantado; tiempo para matar y tiempo para curar, tiempo para demoler y tiempo para edificar; tiempo para llorar y tiempo para reír, tiempo para gemir y tiempo para bailar; tiempo para lanzar piedras y tiempo para recogerlas, tiempo para los abrazos y tiempo para abstenerse de ellos; tiempo para ganar y tiempo para perder, tiempo para conservar y tiempo para tirar fuera; tiempo para rasgar y tiempo para coser, tiempo para callarse y tiempo para hablar; tiempo para amar y tiempo para odiar, tiempo para la guerra y tiempo para la paz". Hoy es tiempo de dar y de dar hasta que duela según conocida frase del malogrado mexicano Miguel Ángel Cornejo, démosle a nuestra justicia militar, lo mejor de nuestra capacidad profesional

El Derecho Militar, con la serenidad de su lógica concepción referida a las nuevas realidades de nuestro pueblo, cual cabeza de anciano apoyada en el índice, cabila con preocupación y sugiere la normatividad para así lograr que la aplicación de la justicia militar sea motivo de concordia y no de discordia entre nosotros, pues esto hace que los hombres y mujeres de Derecho comprendamos la trascendencia de incursionar en el estudio de esas nuevas vivencias jurídicas que nos plantea un escenario en permanente cambio y para que la justicia militar que intentamos reforzar juntos, se proyecte a nuestro pueblo con sentido filial y que contribuya a unirnos, pero que lo haga de verdad, con esa verdad que sólo el Derecho posee y que se concretiza en auténtica justicia.

\section{CONCLUSIONES}

"Quisiera poder hacer la narración histórica de este esfuerzo, en esta epopeya, con función higiénica, con el valor purificador de una confesión, pero ello excede largamente las limitaciones de un artículo, además ni la ocasión ni el espacio asignado me permiten tal engolosinamiento”. ${ }^{42}$

Termino parafraseando al Historiador peruano Jorge Basadre ${ }^{43}$ cuando dice "Hay temas para ser planteados y temas para ser agotados, temas que se horadan y temas que se vacían". Pienso que los de la justicia castrense son del primer grupo.

42. Arturo Giles, "Epílogo Oteando el futuro de la justicia militar en América”, Op. cit., 124.

43. Jorge Basadre, "Conversación con un grupo de profesores y alumnos del Programa Académico de Derecho de la Pontificia Universidad Católica del Perú”, el 25 de Junio de 1974. 
Finalmente, Calderón de la Barca en "La vida es sueño", dice: "sueño que estoy aquí, de estas prisiones cargado; y soñé que en otro estado más lisonjero me vi. ¿Qué es la vida? Un frenesí. ¿Qué es la vida? Una ilusión, una sombra, una ficción, y el mayor bien es pequeño; que toda la vida es sueño, y los sueños, sueños son”. Que los sueños de nuestros padres por un Perú fraterno, justo y unido, inspiren e iluminen nuestro camino, para actuar siempre con rectitud, altura y dignidad en las luchas por la justicia, esa estrella polar que a veces resulta tan inalcanzable, en ese trabajo con frecuencia incomprendido, poco difundido y en solitario, en ese servir a la verdad, en ese jugar a ser Dios que significa administrar justicia, pero no importa, pues lo que se pierde en fama se gana en eternidad y ello permite entrar por derecho propio en la galería mística del recuerdo y la gratitud de las futuras generaciones. En esta empresa, en que, como anotaba Jefferson, "todos somos uno" y yo podría agregar, integrados por una visión común "la paz".

\section{REFERENCIAS}

- Araya Escobar, Cristián. "Bases jurídicas del nuevo código de justicia militar de Chile". En El Jurista del Fuero Militar Policial, publicación académica del Centro de Altos Estudios de Justicia Militar Año V, número 7/ julio (2016), Lima. IMAGIDEAS.COM. 116.

- Basadre, Jorge. "Conversación con un grupo de profesores y alumnos del Programa Académico de Derecho de la Pontificia Universidad Católica del Perú”, el 25 de Junio de 1974.

- Biscaretti Di Ruffia, Paolo. Introducción al Derecho Constitucional Comparado (Las "formas de Estado" y las "formas de gobierno". Las Constituciones modernas), México: Fondo de Cultura Económica, 1975.

- Defensoria del Pueblo. Informe Defensorial No.6, Lineamientos para la reforma de la justicia militar en el Perú. Lima: Editorial Trama Azul Editores, 1998. Expediente No 0023-2003-PI/TC. https://doi.org/10.21669/tomo.v0i0.5230

- Fernández Segado, Francisco. "La Jurisdicción Militar en la Constitución española 1978. Su organización y ámbito competencial”. En Jurisdicción Militar y Constitución Iberoamericana, 131-232. Lima: Grijley, 1997.

- Giles Ferrer, Arturo Antonio. "Apuntes para un estudio acerca de la justicia militar en el Perú”. En El Jurista del Fuero Militar Policial, número 2, noviembre (2013): 89-98.

"Epílogo Oteando el futuro de la justicia militar en América". II Foro Interamericano sobre justicia militar y derecho operacional, (2014):117-126. Lima: Centro de Altos Estudios de Justicia Militar.

- Hitler, Adolf. Mi Lucha, Tomo I y II. Alemania: Editorial Seckerand Warburg.

- Ley de Organización y Funciones del Fuero Militar Policial, aprobada por Ley 29182, modificada parcialmente por la Ley 29955. 
- Loewenstein, Karl. Teoría de la Constitución. Barcelona: Ariel, 1986.

- $\quad$ Lucas Verdú, Pablo. Curso de Derecho Político. Vol. I. Madrid: Editorial Tecnos, 1972.

- Ortega y Gasset, José. España Invertebrada. Barcelona: Espasa Libros, S.L.U.

- Rodríguez-Villasante y Prieto, José Luis. "Estudio de Derecho comparado sobre la organización de la jurisdicción militar en diversos países". En Revista Española de Derecho Militar (REDEM), N53, Tomo I, enero-junio (1989): 57 y sigs.

- $\quad$ Rousseau, Juan Jacobo. EL contrato social. Lima: Mercurio S.A., Lima.

- Sánchez Agesta, Luís. Curso de Derecho Constitucional comparado. Facultad de Derecho, Universidad Complutense de Madrid: 5ª ed., 1973.

- $\quad$ Ugarte del Pino, Juan Vicente. Historia de las Constituciones del Perú. Lima: Andina S.A., 1978.

RECIBIDO: $10 / 03 / 2020$

APROBADO: $12 / 05 / 2020$ 